\title{
AN INVESTIGATION INTO THE EFFECTS OF STRESS ON THE DYNAMICS OF SELECTED XHOSA FAMILIES
}

\author{
NE SOKHELA
}

\section{INTRODUCTION}

Family theories have been developed from Western communities to describe the functioning of families but are used in the treatment of families all over the World. Results in various studies reveal that stress contributes to the development of health/illness behaviours within the family. These theories have also been used in the training of therapists including those working with Xhosa families.

There is no literature that describes the functioning of a Xhosa family and effects of stress in the dynamics of Xhosa families. These dynamics are important in describing the way the family functions, how stress develops and manifests itself in different families.

Application of Western theories uncritically to Xhosa families could lead to difficulties in therapy as there is no understanding on how families function and how symptoms develop and present.

Westem families according to literature function on a model of increasing individualism, accepted as a standard of maturity by society. The nuclear family is the central unit of focus, with the extended family usually physically external, although emotionally internal.

The effects of using family dynamic concepts were discovered in a study on schizophrenia in which it was discovered that schizophrenia improved when family functioning and relations were good (Jones 1980) and that in dealing with childhood behaviour problems it was difficult to deal with the child alone but to include family members to alleviate stress.

\section{Conceptual Framework}

The dominant theoretical framework used in this study is the structural approach by Munichn and the systems approach by Bowen. From these theories the concepts describing the dynamics of families are discussed as they occur normally and under stress.

\section{The Systems Theory}

Bowen in Guerin (1976) describes the family as the system in which every activity produces a reaction in one or more of its members. This system includes not only the family but also relatives. Every member is presumed to play a role which is relatively stable. A member has a degree of personal differentiation from family of origin, the ability to be one's self in the presence of pressure that threatens the loss of love or social position. Some families use scapegoating on one member by blaming him for the family problems. This pressure can lead to the development of symptoms of either physical or emotional illness in the family member. If this member improves another member is likely to absorb the pressure and develop symptoms.

\section{The Structural Theory}

Munichin views the family as single interrelated systems in terms of:

* hierarchy of power which describes how power is shared between parents and children and between the spouses.

* clarity and firmness of boundaries between children and their parents.

* family tolerance of one another

The concepts found in the two approaches are discussed below:

\section{STRUCTURAL CONCEPTS}

Triangles

A small stable emotional unit of the family in a two person system. It remains stable as long as the relations are calm. Once the stress increases within the system one person becomes uncomfortable and pulls a third person into the emotional unit to relieve the tension between the marital pair. A calm triangle is the one that consists of two people and an outsider. Bowen explains that the favourable position in a triangle is to be a member of the two-some but under stress it is comfortable to be an outsider as there is a chance to withdraw from conflict. The emotional system in a triangle reflects the conflicts and relationships of the family.

Mental illness results when a triangle is tense and relations are negative.

\section{Boundaries}

A rule describes who should participate in a family subsystem (Munichin 1974). Normally family members in a subsystem have a contact with each other but function independently from each other. In pathological family functioning this contact is normal in the form of either too much contact or no contact at all. Subsystems of importance as explained by Glick and Kassner (1974) are those of children on one side and on parents on the other hand. Roles towards each of the spouses in the subsystem are defined. The emotional relationship between a child and an adult differ from child to child relationship.

In a disturbed family system adults may pull children into adult subsystems so that parents leave important decision making on children. Sometimes children are pulled in to play adult roles thus depriving them of childhood developmental task. Boundaries may also be blurred leading to lack of autonomy on the child and over involvement of the parent concemed.

\section{Coalitions}

This is a bond of support that exists within the family which develops over a period of time (Munichin 1974). The common coalitions are:

* marital coalition - which keeps the family functioning

* parental coalition - which keeps the spouses together

* siblings coalition between specific offsprings

* sex coalitions between mother and daughter. father and son

Parent-parent coalitions are stronger than parent-child coalitions. Coalitions enable the members to learn interpersonal skills.

In disturbed families the parent-child coalitions may be stronger than parent-parent coalition leading to decrease in communication between spouses and lack support and responsiveness.

\section{DYNAMIC CONCEPTS}

\section{Power}

An amount of freedom given to a member to make decisions and rules that have to be followed by a family (Jones 1980). Each role played by a member has responsibility and accountability. Power is attached to most roles. Unwritten laws exist between the marital partners known by all family members on who has power on a specific area.

In dysfunctional families power may be vested on one member only to make all family decisions thus preventing others from making decisions in 
their areas. This leads to ineffective functioning of the other spouse. When there is no agreement there is a struggle for power to an extent that every decision becomes a battle.

\section{Roles}

This is a culturally determined function of each member of a family which can also be sex linked. Roles develop in children by allocation of sex linked roles by parents at a very early age, and also due to identification with the parent of the same sex (Jones 1980) There are role expectations for all sexes e.g. the father is expected to be strong and instrumental while the mother is expected to be affectionate and expressive. The family role function is normal if the necessary roles are fulfilled and accepted.

When the necessary functions are not met e.g. a weak man dominated by his wife thus unable to play a role of a father to his son or a cold mother unable to demonstrate affection, the family function is disturbed.

\section{Differentiation}

Bowen (in Guerin 1976) explains that in a normal person the emotional and intellectual systems function in co-operation and decisions are based on thoughts. Differentiation also includes the development of self in a person with an amount of solid self than others.

Differentiation differs on a continum expressed as a differentiation of self scale.

Lower in the scale are people more vulnerable to stress said to be poorly differentiated. Their primary goal is centred around love, security, comfort and happiness and make decisions based on emotions. Much of their energy is spent on seeking love and attacking others for not providing it. Low differentiated people in marriage fuse into an undifferentiated ego mass, seeking self from the partner in the form of stuck togethemess of a nuclear family. One member borrows self from the other in order to function better than before, leaving the other functioning below the original level of functioning, a symptom of mental illness. A state of dependence develops with the over functioning member carrying the burden. A form of reaction to stress in this marital conflict leads to divorce or projection of the lack of differentiation to one or more children usually a child who is in the triangle.

High up in the scale are people more autonomous who spend more energy in goal directed activities. They can differentiate between feelings and reality and are less sensitive to praise or criticism because they have a realistic evaluation of themselves.

\section{Communication}

This is an exchange of ideas from one person to the other either verbally or through body language. Abnormal patterns of communication exist leading to inability of family members to express trust and love. The following patterns are often found:
* blaming - the person deals with stress by criticising and telling the other who the boss is.

* placating - a tendency to agree to a point, nor matter at which cost in order to keep peace.

* supereasonableness - a person who behaves as if everything is alright while he/she feels hurt inside.

* irrelevant- replies with answers not related to the topic at hand.

In addition to the above abnormal forms of communication there may be no communication at all.

\section{TERMINOLOGY USED}

\section{Family of origin}

This refers to the family in which each spouse is a sibling and includes mother, father, siblings, stepmother and stepfather.

\section{Time out}

In this study this refers to the time taken by each spouse to be away from the other spouse for a short period with friends or in a social interaction to enable tempers to cool down and for communication to be resumed.

\section{Cooling off}

In this study the time taken by a spouse to go out to be alone after a quarrel in order to reason alone to allow the temper to cool down.

Healthy families Normal families

A family with no mentally ill member in this study

Nuclear family

A family unit composed of spouses and their children.

\section{Extended family}

A family with various nuclear families and other relatives such as the inlaws, aunts and uncles

\section{ADM OF THE STUDY}

The aim of the study was to describe the effect of stress on the dynamics of selected Xhosa families.

\section{RESEARCH METHODOLOGY}

\section{Objectives}

* To describe the effect of stress on the dynamics of selected Xhosa families

* To investigate whether the concepts used to describe the family dynamics from Western theories could be used in describing Xhosa families.

\section{RESEARCH DESIGN}

A descriptive approach was used in which case studies were done on ten families. In each family a study of structural and dynamic concepts was done when there was no stress and in the presence of stress. A genogramm was drawn for each family for three generations for both spouses in order to demonstrate the pattern of relationships.

\section{DATA COLLECTION METHOD}

A flexible interview guide was used by the researcher. This guide covered the concepts under study. It was important that the researcher conducted the interviews personally as there was need to discuss the family functioning in a form of a conversation. No direct questions could be used in the participant's language that could describe the concepts. This enabled the researcher to be non-directive in order to obtain the respondents belief related to each concept.

Each respondent was interviewed separately to encourage freedom of expression of even sensitive issues. Information obtained was regarded confidential from the other spouse if he/she so wishes. This method was chosen because facts, impressions and beliefs of respondents were needed.

\section{SAMPLE SIZE AND DESCRIPTION}

Five families with a mentally ill family member and five families with no mentally ill member formed the sample. The spouses in all groups were Transkeian Xhosas who had been resident in any one town or village in Transkei for at least five years at the time of study.

The families with a hospitalised member were selected conveniently from male and female admission wards of a psychiatric hospital and consisted of three females and two male patients and their families.

The control group was selected from church organisations and members of the staff. This method was used as it was possible for the researcher to identify healthy families during day to day interactions as a member. In order to be able to compare families from both groups the educational standard and income had to be the same. Two members out of five inpatient groups were from the middle income group with the same educational level. Two families from the control group fell in the same category while the rest of both healthy and inpatient groups were of low socio economic income group.

This was done in order to prevent bias in the belief and the impression of respondence due to differences in income and level of education.

\section{THE RESULTS}

The results shown in Table A below demonstrate how the concepts were used by both groups of families in times of stress. 


\section{UTILIZATION OF CONCEPTS FROM WESTERN THEORIES}

The concepts developed from Western Theories were easily applicable to describe and analyse the functioning of Xhosa families. They were found to be useful and relevant to describing family life by both the researcher and the families interviewed and to differentiate reactions to stress from both sets of families. Even concepts like differentiation which seems to be far removed from life in an extended family, proved to differentiate between normal and problem families.

The question of family therapy was not addressed in this study. Although Xhosa families can now be analysed and described, therapeutic interventions may need to be adapted to suite the health/illness behaviour of these families. Further studies are therefore recommended to address therapy for this group.

\section{IMPLICATIONS FOR NURSING}

The study of family systems should be part of the curriculum in psychiatric nursing to enable the nurses to understand how the family functions as a unit. Nurses will be able to identify health illness behaviours as a result of unhealthy family functioning and to prevent the occurrence of serious symptoms. The client must be treated as a member of a system, taking into consideration that the symptoms may be a reaction to serious abnormal family interactions. In order for such behaviours to be understood and handled the whole family must be put into the picture. Symptom bearers can easily be identified during an interaction with the client so that not only the member is managed but also his family, to improve family relations. This has been proved to be important in the care of people with psychological disturbances. Nurses are in a pivotal position to manipulate and enhance family coping and reduce stress.

\begin{tabular}{|c|c|c|c|}
\hline & HEALTHY FAMILIES & & PROBLEM FAMILIES \\
\hline$\square$ & $\begin{array}{l}\text { utilize both inlaws or time out or cooling } \\
\text { off in times of stress. Cooling off enables } \\
\text { spouses to cool down tempers for } \\
\text { communication to occur. }\end{array}$ & $\square$ & $\begin{array}{l}\text { utilize family of origin causing a rift in } \\
\text { marital relations. }\end{array}$ \\
\hline $\mathbf{0}$ & $\begin{array}{l}\text { Friends are calted in to neutratize tempers } \\
\text { to that spouses are able to communicate } \\
\text { and discuss conflict. }\end{array}$ & $\square$ & $\begin{array}{l}\text { triangle-in members of their church to } \\
\text { solve the problem and include them in } \\
\text { conflicts. }\end{array}$ \\
\hline$\square$ & $\begin{array}{l}\text { traditional male and female roles exist } \\
\text { with men agreeing to sharing roles. }\end{array}$ & $\square$ & $\begin{array}{l}\text { roles are confused with spouses not clear } \\
\text { about their roles. }\end{array}$ \\
\hline$\square$ & $\begin{array}{l}\text { men have most power and grant females } \\
\text { a certain amount of power to achieve } \\
\text { family goals. A strong marital relationship } \\
\text { exist between spouses. }\end{array}$ & $\square$ & $\begin{array}{l}\text { there is power struggle between spouses } \\
\text { or power is given to one spouse leaving } \\
\text { the remaining spouse with no power at all } \\
\text { or power is lodged in a member of the } \\
\text { family of origin. Very poor marital } \\
\text { relationship. }\end{array}$ \\
\hline ם & communication is open. & $\square$ & $\begin{array}{l}\text { communication is broken down with most } \\
\text { communication taking the form of fights. }\end{array}$ \\
\hline ص & $\begin{array}{l}\text { healthy spouses are more differentiated } \\
\text { and more of them give preference to } \\
\text { nuclear family as opposed to family of } \\
\text { origin. }\end{array}$ & $\square$ & $\begin{array}{l}\text { spouses are low on differentiati- on scale } \\
\text { and always refer to family of origin in } \\
\text { thought and action. }\end{array}$ \\
\hline$\square$ & there is clear generation boundary. & $\square$ & $\begin{array}{l}\text { there is no boundary between children } \\
\text { and their parents. }\end{array}$ \\
\hline
\end{tabular}

Table A: Results showing differences in the utilization of concepts by healthy families and problem families

\section{LIMITATIONS OF THE STUDY}

Since a comparison between healthy and problem families was needed it was not possible to obtain a bigger sample of people from the inpatient group and healthy families who can easily be compared. Another factor was that the sample needed clients on whom family therapy was used as a treatment method in addition to other methods from the inpatient group, and only five inpatients could be found.

\section{REFERENCES}

Glick, I.D. and Kessler, D.R. (1974): Marital and Family Therapy, Yew York: Grune Stration.

Guerin, P. (1976): Family Therapy- Theory and Practice, Yew York: Gardener Press.

Jones, S. (1980): Family Therapy: A comparison of Approaches, London: Prentice Hall.

Nobesuthu Effie Sokhela Faculty of Medicine \& Health Sciences Department of Nursing Science UNITRA 